\title{
Synthesis and mineralogical characteristics of hydroxylapatite-hydroxylpyromorphite solid solution series $\mathrm{Ca}_{5}\left(\mathrm{PO}_{4}\right)_{3} \mathrm{OH}-\mathrm{Pb}_{5}\left(\mathrm{PO}_{4}\right)_{3} \mathrm{OH}$
}

\author{
Joanna Motyka, Joanna Oknińska, Maciej Manecki
}

AGH University of Science and Technology, Faculty of Geology, Geophysics and Environmental Protection, Department of Mineralogy, Petrography and Geochemistry; al. Mickiewicza 30, 30-059 Krakow, Poland; e-mail: joannaokninska@onet.pl

(C) 2015 Authors. This is an open access publication, which can be used, distributed and reproduced in any medium according to the Creative Commons CC-BY 4.0 License requiring that the original work has been properly cited.

Lead is a widespread environmental contaminant toxic to living organisms. Soils and wastes contaminated with $\mathrm{Pb}$ are found in both rural and urban settings. Uptake of $\mathrm{Pb}$ from waste, soil or water by phosphate compounds, particularly hydroxylapatite, has been proved as effective remediation strategy (Xu \& Schwartz 1994). The technology arises from the low solubility of lead apatites and from their rapid precipitation reactions.

The structure of the apatite group minerals can be described by the general formula $\mathrm{A}_{5}\left(\mathrm{BO}_{4}\right)_{3} \mathrm{C}$, where positions $\mathrm{A}, \mathrm{B}, \mathrm{C}$ can be substituted by e.g. A: $\mathrm{Ca}, \mathrm{Pb}, \mathrm{Sr}, \mathrm{Ba}$; B: $\mathrm{P}, \mathrm{As}, \mathrm{V} ; \mathrm{C}: \mathrm{Cl}, \mathrm{OH}, \mathrm{F}$, $\mathrm{Br}$, I. Apatites are very tolerant to structural distortion resulting from chemical substitution in cationic and anionic positions and consequently they are remarkably diverse in composition. Thanks to this potential for extensive solid solutions in the system, the lead apatites precipitating in the environment are not pure end members but rather $\mathrm{Pb}-\mathrm{Ca}$ solid solutions.

A complete solid solution between hydroxylapatite (HAP) and hydroxylpyromorphite (HPY) was determined before (Bigi et al. 1991, Hadrich et al. 2001). The results, however, are still fragmentary. The objective of the project is systematic characterization (crystal structure and infrared and Raman vibrational properties) of synthetic analogs of the minerals from HAP-HPY solid solution series. This will allow clarifying the controversies related to the change of properties towards substitution of lead for calcium. Well characterized products of the synthesis will be used in further thermodynamic study of solubility changes with substitution, which was never determined before.

It is assumed that the properties vary in systematic way with $\mathrm{Pb}$ substitution for $\mathrm{Ca}$. An effective wet method of synthesis of $\mathrm{Ca}-\mathrm{Pb}$ apatites was developed. A crystalline, homogeneous precipitates with stoichiometric composition were produced. Six phases of HAP-HPY solid solution series were prepared by dropwise mixing of a solution containing calcium and/or lead ions and a phosphate solution at room temperature. During the synthesis $\mathrm{pH}$ of 8.5 was maintained using $\mathrm{NH}_{4} \mathrm{OH}$. Precipitates were washed, air dried and characterized by scanning electron microscopy (SEM) with the energy dispersive spectroscopy detector (EDS), powder X-ray diffraction, infrared spectroscopy (FTIR) and Raman spectroscopy.

All synthetic products obtained in the experiments form hexagonal needles less than $0.1 \mu \mathrm{m}$ long. Elemental composition of six product phases is consistent with the objectives of the experiment. X-ray diffraction patterns reveal a shift toward lower angles $2 \theta$ for phases with higher lead contents. This indicates an enlargement of the lattice constants. The variation of parameters, however, is not linear (does not follow the Vegards law). Particularly the cell parameter $c$ changes more for phases reach in lead. These results are in agreement with those reported previously (Bigi et al. 
1991, Hadrich et al. 2001). A shift of band position is also observed in both FTIR and Raman spectra. All the bands shift towards lower wave number with increasing $\mathrm{Pb}$ content. In most cases the shift is not linear exhibiting two trends similar to those of crystal lattice parameters. This may indicate that the vibrational properties of the phases in the series depend stronger on the bond length than on the atomic mass of substituting elements.

This work was supported by AGH UST statutory grant No. 11.11.140.319.

\section{REFERENCES}

Bigi A., Gandolfi M., Gazzano M., Ripamonti A., Roveri N. \& Thomas S.A., 1991. Structural Modyfications of Hydroxyapatite induced by Lead Substitution for Calcium. Journal of the Chemical Society, Dalton Transactions, 11, 2883-2886.

Hadrich A., Lautié A. \& Mhiri T., 2001. Vibrational study and fluorescence bands in the FT-Raman spectra of $\mathrm{Ca}_{10-\mathrm{x}} \mathrm{Pb}_{\mathrm{x}}\left(\mathrm{PO}_{4}\right)_{6}(\mathrm{OH})_{2}$ compounds. Spectrochimica Acta Part A: Molecular and Biomolecular Spectroscopy, 57, 8, 1673-1681.

Xu Y. \& Schwartz F. W., 1994. Lead immobilization by hydroxyapatite in aqueous solutions. Journal of Contaminant Hydrology, 15, 3, 187-206. 